\title{
Kinematics of the crust in southern Tibet and Higher Himalayan Crystalline -a paleomagnetic approach
}

\author{
Rachida El Bay ${ }^{*}$, Erwin Appel ${ }^{1}$, Rodolfo Carosi ${ }^{2}$, Lin Ding ${ }^{3}$, Dunkl Istvàn ${ }^{4}$, Richard Gloaguen ${ }^{5}$, \\ Chiara Montomoli², Lalu Paudel ${ }^{6}$ and Bastian Wauschkuhn ${ }^{5}$
}

\footnotetext{
1 Institute for Applied Geoscience, University of Tuebingen, GERMANY

2 Departimento di Scienze della Terra, University of Pisa, ITALY

3 Institute of Tibetan Plateau Research, Chinese Academy of Sciences, CHINA

${ }_{4}$ Geoscience Center, University of Goettingen, GERMANY

5 Institute for Geology, Technical University of Freiberg, GERMANY

${ }^{6}$ Central Dept. of Geology, Tribhuvan University, Kathmandu, NEPAL

* For correspondence, email: rachida.el-bay@uni-tuebingen.de
}

Secondary pyrrhotite remanences from the Tethyan Himalaya acquired during Eocene (western Himalaya) and Oligocene to early Miocene (central and eastern Himalaya) were evaluated for block rotations. Oroclinal bending is well reflected by paleomagnetic data in the western part of the Himalaya also showing a uniform counterclockwise rotation of India versus the Tethyan Himalaya. In contrast, data from the central part and preliminary results from the eastern part indicate an abrupt change to unexpected clockwise rotations versus India where oroclinal bending would predict no rotation or slight counterclockwise rotations (Schill et al. 2004). It can be hypothesized that these clockwise rotations are a result of a large dextral shear zone related to lateral extrusion of the Tibetan Plateau, with an onset in central Nepal. However, the existing gap in suitable data from the eastern part of the Himalaya was hindering a closer evaluation of this question. The hypothesis is reconsidered in the light of new findings.

In southern Tibet field work has been carried out on an E-W section between $86^{\circ}$ and $89^{\circ} \mathrm{E}$ (Figure1) encompassing the Nayalam section, the Karta valley, the Dinggye extentional zone and the Yadong/ Pagri area. Low grade Ordovician to Mid-Triassic metacarbonates and slates were sampled. The south Tibetan series are bounded to the south by the South Tibetan Detachment System (STDS) and to the north by the Yarlung Tsangpo Suture Zone (YTSZ) and there is a widespread occurrence of north Himalayan gneiss domes. The S$\mathrm{N}$ transect at ca. $87^{\circ} \mathrm{E}$ is ranging from few $\mathrm{km}$ south of Lukla (Solu Khumbu, HHC) to Lhatse close to the YTSZ. Sampling included the high grade metamorphic gneisses from the HHC, the Tethyan sedimentary series (Ordovician to Carboniferous) and the upper Triassic flysch between Tingri and Lhatse.

The mechanism of secondary remanence acquisition in lowgrade metamorphic rocks of the Tethyan Himalaya is quite well understood. Pyrrhotite is formed during prograde metamorphism. A thermoremanence is blocked during last cooling if the peak metamorphic temperature has reached the Curie temperature (Tc) of pyrrhotite (ca. $320^{\circ} \mathrm{C}$ ). If the peak temperature was lower than Tc a thermo-chemical mechanism is likely and the time of remanence acquisition might predate the cooling age. For these reason we applied illite crystallinity and $\mathrm{K} / \mathrm{Ar}$ dating to determine peak metamorphic temperatures and ages of metamorphic cooling. In the high grade gneisses of the HHC pyrrhotite is believed to be formed during the transition from ductile to brittle deformation (retrograde stage). A thermoremanence is likely acquired and its age

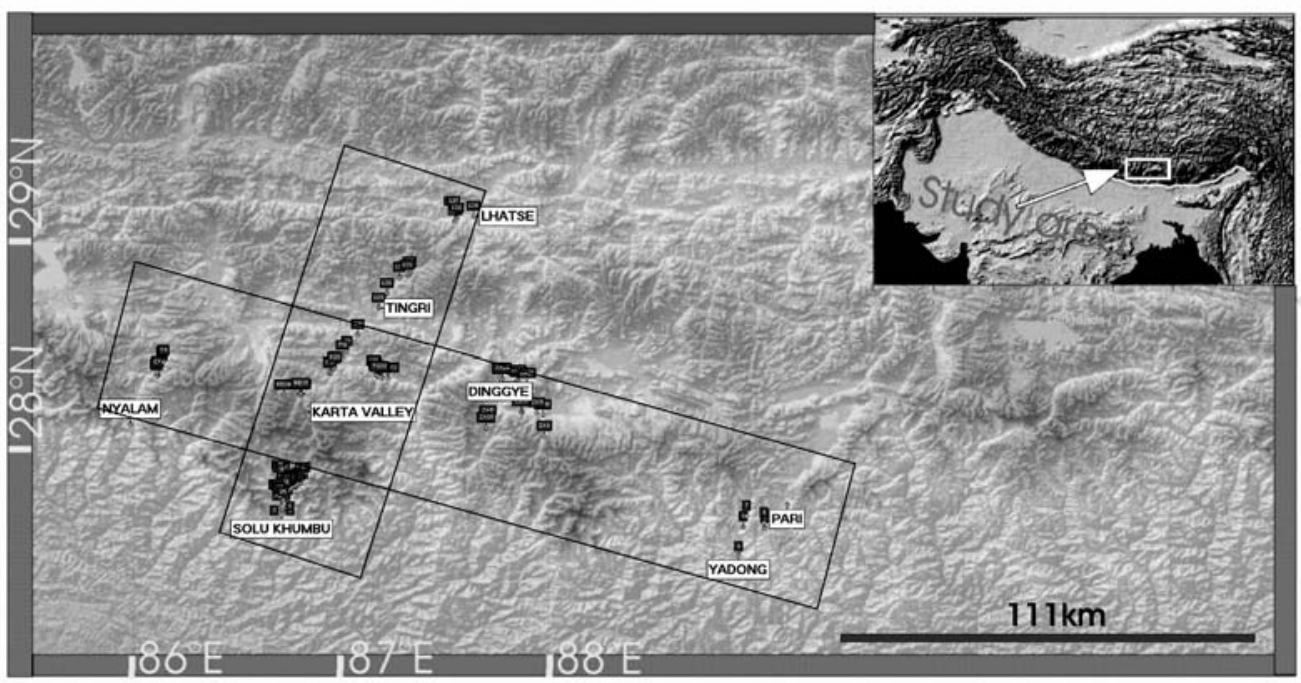

FIGURE 1. Shutle Radar Topography Mission (SRTM) image from the study area showing sampled $\mathrm{E}-\mathrm{W}$ traverse and S-N transect 
will correspond to the age of the last metamorphic cooling event.

"Anomalous" inclinations, indicating strong tilting after remanence acquisition, are observed across the E-W traverse. Taking into account the proximity of the sampled sites to the STDS, especially at the Nyalam section (Nyalam detachment) and in the Karta valley, a regional trend linked to a "folded" STDS can be assumed. Therefore, remanence acquisition predates the onset of the STDS or is coeval with it.

Remarkably, remanences are mainly dispersed on small circles with a tilt axis oriented approximately in N-S direction. This is not in agreement with long-wavelength tilting parallel to the strike of the main Himalayan tectonic units. It can be suggested that this small-circle distribution is an expression of doming in the crust (caused by channel flow?).

Inclinations at Nyalam section and Karta valley indicate a second phase of tilting superposed to the E-W tilting.

Small circle analysis (Waldhör et al. 2006) enables quantification of vertical axis rotation. A clockwise rotation is evident along the $\mathrm{S}-\mathrm{N}$ transect at $\mathrm{ca} .87^{\circ} \mathrm{E}$ at Karta valley and further north in the flysch series between Tingri and Lhatse. First results from the northern part of the HHC in Khumbu area indicate a pattern of rotation comparable to those observed at the Karta valley. Counterclockwise rotation obtained for the Dinggye- and Yadong/Pagri areas are in contradiction with the above mentioned hypothesis of a uniform large dextral shear zone.

In summary, the hypothesis of a large dextral shear zone linked to the extrusion of the Tibetan Plateau can be yet not proved or rejected. A major effect attributed to a normal fault/ thrust system became more evident.

\section{References}

Schill E, E Appel, C Crouzet, P Gautam, F Wehland and M Staiger. 2004. Oroclinal bending and regional significant clockwise rotations of the Himalayan arc - constraints from secondary pyrrhotite remanences. Geological Society of America Special Publication on orogenic curvature

Waldhör M and E Appel. 2006. Intersection of remanence small circles: new tools to improve data processing and interpretation in paleomagnetism. Geophysical Journal International 33-45 